\title{
Mandated Actions, Legitimate Role-Bearers and Expected Actor Networks in the Management of Infectious Disease Epidemics: The Case of Marburg Virus Disease in Uganda.
}

Steven Ssendagire ( $\nabla$ sssendagire@musph.ac.ug )

Doreen Tuhebwe

Makerere University School of Public Health https://orcid.org/0000-0002-9464-2340

\section{Susan Babirye}

Makerere University School of Public Health

Rebecca Nuwematsiko

Makerere University School of Public Health

Andrew K. Tusubira

Makerere University School of Public Health

Joshua Kayiwa

Public Health Emergency Operations Center, Uganda Ministry of Health

Aloysius Ssennyonjo

Makerere University School of Public Heath, Supporting Policy Engagement fir Evidence-Based

Decisions (SPEED) Project

Issa Makumbi

Public Health Emergency Operations Center, Uganda Ministry of Health

Freddie Ssengooba

Makerere University School of Public Health, Supporting Policy Engagement for Evidence-Based

Decisions (SPEED) Project

Research article

Keywords: Epidemic Management, Coordination, Actor-networks, Mandated-actions, Role-bearers, Uganda

Posted Date: April 23rd, 2020

DOl: https://doi.org/10.21203/rs.3.rs-22886/v1

License: (c) (i) This work is licensed under a Creative Commons Attribution 4.0 International License.

Read Full License 



\section{Mandated Actions, Legitimate Role-Bearers and Expected Actor Networks in the Management of Infectious Disease Epidemics: The Case of Marburg Virus Disease in Uganda.}

\section{Authors}

Ssendagire Steven ${ }^{1}$, Tuhebwe Doreen ${ }^{1}$, Babirye Susan ${ }^{1}$, Nuwematsiko Rebecca ${ }^{1}$, Tusubira K. Andrew ${ }^{1}$, Kayiwa Joshua ${ }^{3}$, Ssennyonjo Aloysius ${ }^{1,2}$ Makumbi Issa $^{3}$ and Ssengooba Freddie ${ }^{1,2}$

\section{Corresponding Author}

Ssendagire Steven, sssendagire@musph.ac.ug, +256(0)700373285

\section{Affiliation}

${ }^{1}$ Makerere University School of Public Health

${ }^{2}$ Supporting Policy Engagement for Evidence-Based Decisions (SPEED) Project

${ }^{3}$ Public Health Emergency Operations Center (PHEOC), Uganda Ministry of Health

\section{Abstract}

Background

In many Sub-Saharan Africa (SSA) countries, epidemic management is characterized with inaction, confusion and friction among a multitude of participating organizations.

This is partially attributable to the inability to customize international epidemic

management actions and guidelines to local institutional architecture, agencies and

21 relational contexts. This results into poor coordination and suboptimal epidemic

22 management outcomes.

23 Using the case of Marburg Virus Disease (MVD) in Uganda, we explored how to clarify responsibility and collaboration across a multitude of inter-dependent actions and actors

25 during epidemic management.

26 Methods

27 In July 2018, we reviewed MVD management literature and documents to identify key 28 expected actions and actors/agencies. Data was summarized by phase and action area 
1 1) validate the identified actions and 2) assign legitimate role-bearers to each of the

2 validated actions in accordance to the agency mandates in Uganda. Finally, we used

3 NetDraw in UCINet to elaborate the expected network structure among legitimate role-

4 bearers across all the phases and four selected action areas of MVD management.

$5 \quad \underline{\text { Results }}$

6 We validated 304 mandated actions and 79 legitimate role-bearers in MVD

7 management in Uganda. Across the four phases and selected action areas of MVD

8 management, there is a high variation in the identity and number of mandated role

9 bearers. Overall, Ministry of Health headquarters (MoH-HQs), National Task Force

10 (NTF), District task Force (DTF) and National Rapid Response Team (NRRT) are

11 expected to be the most central agencies during MVD management. Across the four

12 phases and the selected action areas, actors are expected to be networked using a

13 core-periphery network structure.

14 Conclusions

15 There is a multitude of agencies required to work inter-dependently to accomplish the 16 mandated actions for MVD management in Uganda. MoH-HQs, NTF and DTF are most

17 central to assume coordination of MVD management in the Ugandan context. It is

18 imperative to build/maintain the information processing, decision making and command

19 and control capacity of these central agencies. The study findings can be used as the 20 basis for exploring compliance and deviation in mandated actions in future MVD 21 epidemics. The methodological approach could be replicated to other infectious disease 22 epidemics in Uganda and beyond. 
1 Key words: Epidemic Management, Coordination, Actor-networks, Mandated-actions,

2 Role-bearers, Uganda

\section{$3 \quad$ Background}

\section{$4 \quad$ The burden of infectious disease epidemics}

5 Infectious disease epidemics are on the rise in Sub Saharan Africa (Fenollar \&

6 Mediannikov, 2018). In 2018 alone, over 95 new outbreaks were reported to World

7 Health Organization (WHO) by member states of the WHO African region. In this same

8 year, Uganda reported the highest number of new epidemics to WHO. These included

9 Cholera, Rift Valley Fever (RVF), Crimean-Congo Hemorrhagic Fever (CCHF), Avian

10 Influenza (HPAI), Marburg Virus Disease (MVD), Meningitis and Anthrax (Mboussou et

11 al., 2019). Frequently, these epidemics are recurrent, in more or less the same location

12 with similar or even greater magnitude. For example, since the year 2000, Uganda has

13 experienced six Ebola Virus Disease (EVD) and five MVD epidemics (CDC, 2020). The

14 last outbreak of MVD in Uganda was in September 2017. More than 40 organizations

15 were drawn to participate in the response. Among others, these included WHO, United

16 States Centers for Disease Control (US-CDC), Médecins Sans Frontières (MSF),

17 Uganda Virus research institute (UVRI), United Nations Children's Fund

18 (UNICEF), United States Agency for International Development (USAID), European

19 Union (EU), Uganda Red Cross Society (URCS), World Vision Uganda (WV),

20 Infectious Diseases Institute (IDI), African Field Epidemiology Network (AFENET),

21 Family Health International (FHI360), Joint Mobile Emerging Disease Clinical Capability 
1 (JMEDICC) and Makerere University School of Public Health (MakSPH) (Ario et al.,

2 2020; MoH, 2017; Nyakarahuka et al., 2019).

3 During the response, the following observations were made; 1) some actors had

4 conflicting roles, 2) some actions were being supported by more than one actor, yet, 3)

5 other actions were left unsupported. At some point during the response, unnecessary

6 friction was also observed; to the extent that some actors were temporarily recalled from

7 the response frontline. This is not unique to the 2017 MVD response in Uganda. Such

8 inaction, confusion and friction have been observed in disease epidemic responses

9 elsewhere in SSA and other Low and Middle Income Country (LMIC) settings (Olu et al., 10 2016; Ross, Welch, \& Angelides, 2017).

11 The inherent challenges with management of infectious disease epidemics in 12 LMICs

13 Broadly, epidemic management in LMICs faces a coordination problem as a result of 14 following related challenges; a) narrow focus on surveillance and response and b) 15 limited clarity on mandate, roles and actors. First, the Integrated Disease Surveillance 16 and Response (IDSR) framework; the strategy through which the majority of LMICs 17 aspire to achieve their epidemic management goals is suboptimal. The framework is 18 premised on a medical model of disease management (Ssendagire, Tuhebwe, 19 Kayongo, \& Ssengooba, 2018). The framework emphasizes epidemic detection and 20 response actions with little attention to the equally important mitigation, preparedness 21 and recovery interventions. After response to an epidemic, little or no attention and 22 resources are dedicated to recovery and prevention of future epidemics. Instead, the 4 I P a g e 
1 system waits to detect and respond to the next epidemic, creating a vicious cycle of

2 epidemic detection and response. By design, therefore, the IDSR framework does not

3 build health systems' resilience to infectious disease epidemics, which we define as the

4 capacity of the health system to prevent, prepare for, respond and recover from the

5 effects of infectious disease epidemics (Kruk, Myers, Varpilah, \& Dahn, 2015).

6 Secondly, in many LMICs like Uganda, there is no published guideline on how

7 tasks/mandates are allocated during epidemic management. When epidemics occur,

8 the commonly observed practice is either to reactively ask available potential actors to

9 indicate the actions they are willing to support or to randomly allocate actions to those

10 physically available actors. This practice does not perfectly match actor competences to

11 specific response actions. It also does not effectively allocate the available resources to

12 all the critical epidemic response actions. Commonly, the required epidemic

13 management actions are not comprehensively defined. Even where attempts to define

14 these actions have been made, the legitimate role-bearers have not been explicitly 15 assigned $(\mathrm{MoH}, 2012)$. This creates the inaction, confusion and friction observed during

16 epidemic management. This culminates into poor coordination and suboptimal

17 epidemic management in LMICs, preventable escalation of epidemics, diversion of 18 resources from other critically important health priorities, more suffering, death, social

19 disruption and loss of revenue due to trade and travel related aversion behaviors 20 associated with escalated epidemics (Frieden \& Damon, 2015; Gostin \& Friedman, 21 2015).

22 Theoretical Framework

5 P a g e 
1 We identify three (3) theories as appropriate for the exploration of the challenges of sub-

2 optimal epidemic management in LMIC settings. These are; 1) Coordination Theory, 2)

3 Network Theory and 3) Comprehensive Emergency Management Theory.

4 Coordination Theory

5 Coordination theory can be applied to predict, understand and influence the process

6 and outcomes of managing dependences between multiple actors. When multiple

7 dependences in form of actions and in form of role-bearers are required to deliver on a

8 single outcome, efficiency of the outcome will likely be constrained. To reduce the

9 likelihood of such constraints, certain structures and processes must be in place before

10 and or during the execution of interdependent actions by multiple role-bearers. These

11 structures and processes are generally referred to as coordination mechanisms.

12 Broadly, there are three coordination mechanisms. These are; 1) Hierarchy (which

13 includes Standardization of required inputs and processes, authority, command and

14 control), 2) Speeding-up information flow (for example through formal and informal

15 networking) and 3) Increasing the capacity for information processing (for example

16 centralization of information processing). To maximize the performance of inter-

17 dependent relationships, the positive contributions from these three broad categories of 18 coordination mechanisms needs to be maximized (Crowston, 1997; Malone \&

19 Crowston, 1994; Melin \& Axelsson, 2005).

20 Network Theory

21 A network is a collection of multiple actors and the relationships that bind them together,

22 and broadly a coordination mechanism also. There are a set of principles that can be 6I P a g e 
1 applied to predict, control and explain the functionality of networks. Provan and Kenis

2 describe three (3) major types of network forms; Shared governance, Lead Organization

3 and Network Administrative Organization (NAO) (Provan \& Kenis, 2008). These network

4 forms correspond to four (4) major network structures; Centralization, Closure,

5 Brokerage and Core/Periphery as described by Nowell and colleagues and as shown in

6 figure 1 (Nowell, Steelman, Velez, \& Yang, 2018).

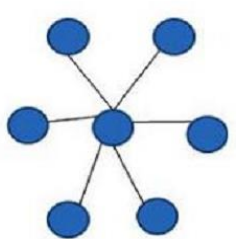

Centralization

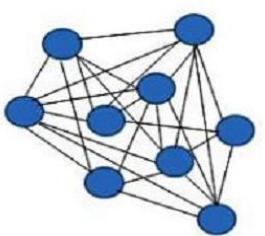

Closure

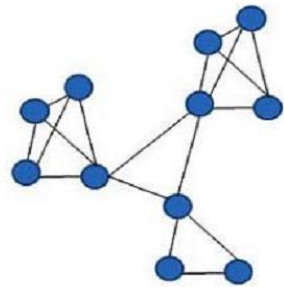

Brokerage

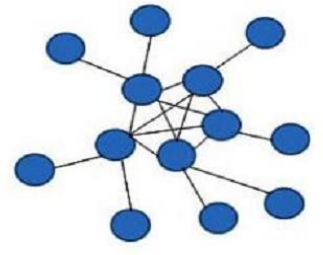

Core/Periphery

Figure 1: Types of Global Network Configuration Structures as described by Nowell and collegues (Nowell, Steelman, Velez, \& Yang, 2018).

Provan and Kenis also contend that different types of network structures are likely to be more effective than others depending on certain contingencies. Such contingencies include the level of trust among actors in the network, the number of actors in the network, the level of goal consensus among the actors in the network and the capacity

12 of these actors to operate in a network (Provan \& Kenis, 2008).

Comprehensive Emergency Management Theory

14 Comprehensive Emergency Management Theory is premised on the coordination mechanism of standardization (Whittaker, 1979). Standardization as a coordination mechanism requires prior identification of all the required emergency management 
1 actions, allocation of these actions to specified role-bearers and developing the capacity

2 of these role-bearers to deliver on their mandated actions. This is the theoretical

3 underpinning of the Emergency Management Cycle (EMC) Model (Waugh, 1999;

4 Whittaker, 1979), which has been found effective in the management of natural

5 disasters like floods and earthquakes (Banipal, 2006; FEMA, 2001).

6 The EMC model specifies four phases of modern emergency/disaster management.

7 These are; 1) Mitigation (actions that prevent a disaster and reduce the chance of it

8 happening, or lessen its damaging effects); 2) Preparedness (actions taken before

9 impact, including development of response plans), 3) Response (actions taken during

10 the initial impact of a disaster, including those to save lives and to prevent further

11 damage to property) and Recovery (actions taken after the initial impact, including those

12 aimed at achieving a return to normality). When the required/mandated actions and the

13 legitimate role-bearers for each of the EMC phases are agreed upon a priori,

14 coordination of emergencies/disasters tends to be more effective compared to when this

15 is not done in advance. Prior assignment of roles creates collaboration, preparedness

16 and clarity; which are all critical to effective emergency management.

17 The study makes a contribution to improved coordination of multiple actions and actors

18 during epidemics management in LMICs. The study addressed three questions. 1) What

19 are the mandated actions in the comprehensive management of MVD in Uganda? 2)

20 Who are the legitimate role-bearers for these mandated actions? 3) How should the

21 legitimate role-bearers be networked?

22 Methodology

8| P a g e 
1 The three methodological approaches used were; 1) Review of MVD management

2 related literature and Documents (July-August 2018), 2) A Delphi survey (March 2019)

3 and Social Network Analysis (SNA).

$4 \quad$ Review of MVD management related literature and Documents

5 To identify the documented mandated actions and legitimate role-bearers in the

6 comprehensive management of MVD in Uganda, we conducted a search and review of

$7 \quad$ MVD management literature and documents.

8 Search strategy

9 We searched online databases using multiple online search strings constructed by 10 combining the terms Marburg, Virus, Disease, Mitigation, Prevention, Preparedness,

11 Response, Recovery, Stakeholders, Actors, Actions, Uganda, WHO, CDC, Outbreak,

12 Epidemic and Resilience. The databases searched included Google, Google Scholar,

13 Pub-Med and Medline. The official websites for WHO, CDC, UNICEF, MSF and MoH-

14 Uganda were also searched for official MVD management related documents. The 15 Uganda Public Health Emergency Operations Centre (PHEOC) also provided 16 documents that were collected during the 2017 Joint External Evaluation (JEE) of 17 International Health Regulation (IHR) core capacities for Uganda.

18 Screening of retrieved Literature and Documents

19 The process and outcomes of screening of the retrieved literature and documents is 20 summarized in Figure 2. First, all the retrieved documents we put into one folder, 21 removed duplicates and screened for relevance of each document by reading their

22 abstracts/executive summaries only. Sixty (60) documents were maintained for full 9| P a g e 
1 reading. The 60 documents were each reviewed separately by two independent

2 researchers (NR and TKA) who abstracted MVD management actions and any role-

3 bearers indicated in these documents.

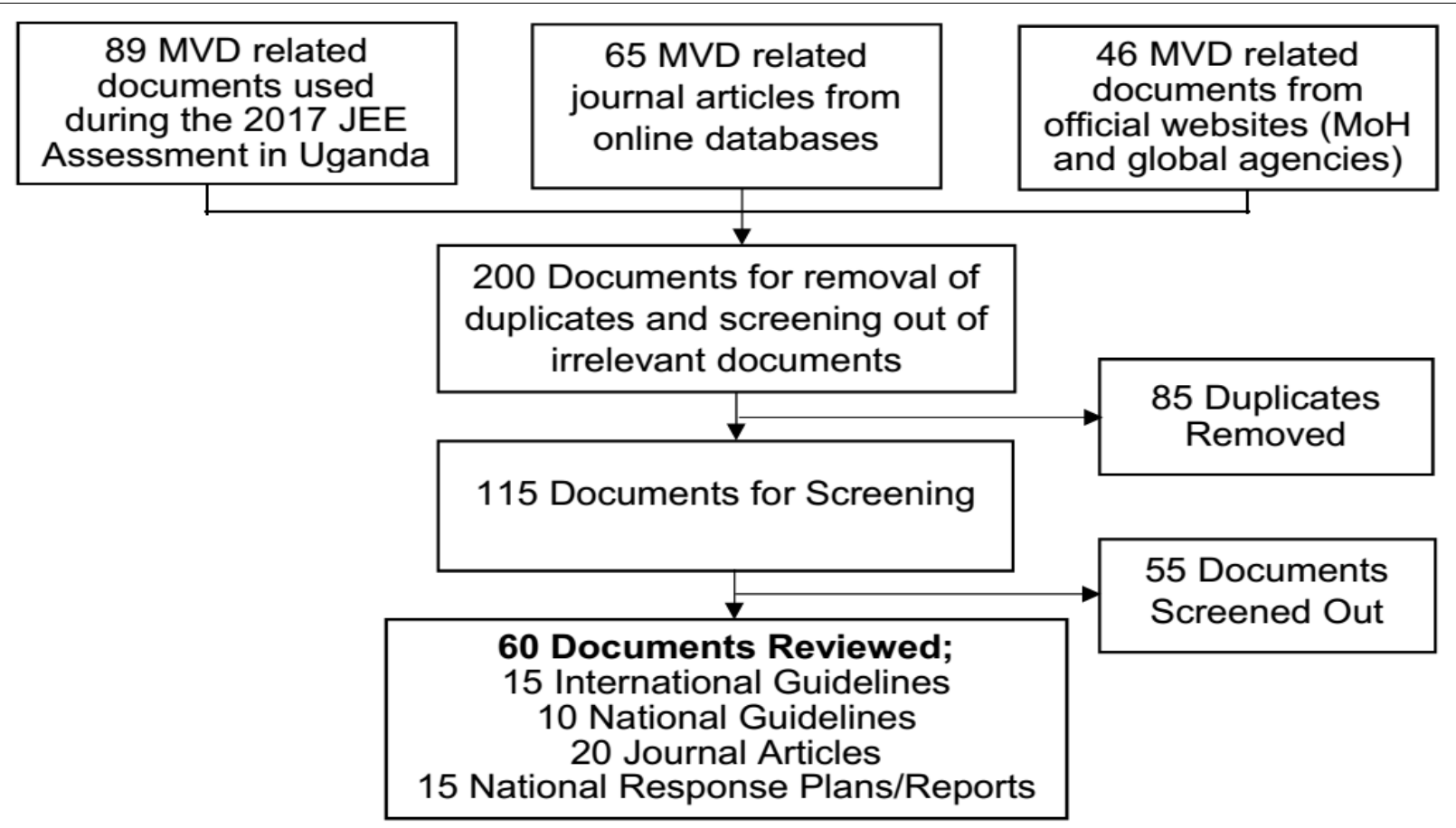

Figure 2: Flow Diagram for identification of documents reviewed as part of the study methodology

5 Any data discrepancies between the two reviewers were resolved by conducting a joint

6 review of the source documents in question. The abstracted data was summarized in

7 excel into a single action-actor matrix with descriptors of phase (Mitigation,

8 Preparedness, Response and Recovery) and action area (as reflected in column 2 of

9 table 3) of MVD management.

10 The Delphi survey

11 We then conducted a 2 round Delphi survey (Giannarou \& Zervas, 2014; Habibi,

12 Sarafrazi, \& Izadyar, 2014) with 30 purposively sampled local experts in MVD $10 \mid \mathrm{P}$ a g e 
1 management drawn from multiple fields to validate and customize the action-actor

2 matrix developed from literature and documentary review. The details of the 30 member

3 Delphi panel are summarized in table 2.

4 Table 2: Characteristics of experts consulted to validate and customize MVD actions 5 and actors identified from reviewed literature and documents

\begin{tabular}{l|lrr}
\hline Variable & Values & $\mathbf{n}$ & \% \\
\hline \multirow{4}{*}{ Practice Domain } & Academia & 5 & 17 \\
& Policy development & 15 & 50 \\
& Implementation & 10 & 33 \\
& Health & 9 & 30 \\
& Prime Minister & 3 & 10 \\
& Agriculture & 12 & 40 \\
& Wildlife & 3 & 10 \\
& Education & 3 & 10 \\
Years in current Position & $\geq 10$ & 8 & 27 \\
& $\geq 5$ & 14 & 46 \\
& $<5$ & 8 & 27 \\
Highest Level of Training & 18 & 60 \\
& Males & 12 & 40 \\
& Female & 3 & 10 \\
& PhD & 24 & 80 \\
& Masters & 3 & 10 \\
& Graduate & 25 & 83 \\
management (years) & $\geq 5$ & 5 & 17 \\
\hline
\end{tabular}

$6 \quad$ First Delphi Survey round

7 Round one of the surveys was a face to face half-day workshop. During this survey, the

8 action-actor matrix generated from reviewed literature and documents was divided into

9 sub-matrices corresponding to the 4 phases (Mitigation, Preparedness, Response and

10 Recovery) of comprehensive MVD management and pinned on the wall to create four

11 respective stations. The workshop participants moved across the 4 stations; adding

12 relevant or deleting irrelevant actions and actors, and indicating the lead and other

13 actors for each of the actions. This was later followed by plenary discussion facilitated 11 | P a g e 
1 by a research team member experienced in facilitating stakeholder deliberations (SF).

2 The workshop outputs were summarized into draft "customized" action-actor matrices

3 for each of the 4 phases of MVD management in Uganda.

$4 \quad$ Second Delphi Survey Round

5 In the second round of the survey, the draft customized matrices were shared by

6 electronic mail to each of the 30 panel members who were asked to send any feedback

7 ladjustments within 2 weeks. All the panel members responded within the stipulated

8 time and their feedback was used to produce the final customized action-actor matrices

9 for comprehensive management of MVD in Uganda. No additional survey rounds were

10 conducted because of the high levels of consensus among panel members after the

11 second round of the survey.

12 Social Network Analysis

13 To explore how the multiple legitimate role-bearers should be networked/aligned to 14 each other during MVD management in Uganda, Social Network Analysis was 15 employed (SNA) (Butts, 2008; Hanneman \& Riddle, 2005). The validated matrices acted 16 as input data. SNA approaches using (NetDraw in) UCINET software were used to 17 visualize the expected interdependencies between the legitimate role-bearers for all the 18 phases of MVD management combined, each of the four phases of MVD management 19 separately and 4 out of the 26 MVD management action areas. The structures of 20 visualized networks were compared to those described by Nowell and collegues (Nowell 21 et al., 2018). The ego-centric quality of the visualized networks was determined using 
1 degree centralization and density. This enabled comparison of the network attributes

2 across the 4 phases and selected action areas.

3 Ethical approval for this study was provided by the Institutional Review Board (IRB) of

4 MakSPH (HDREC Protocol number 580) and granted permission from Ministry of

5 Health Headquarters was also granted (Ref Number ADM.105/309/16). We determined

6 the judicious use of agency names in the findings using the overriding principle of do no

7 harm, practical application of the study and the need for relationship management with

8 known agencies that play key roles in MVD management in Uganda. Participation as a

9 Delphi panel member was voluntary. Informed consent was also sought and 10 documented. We shared the study findings at a national level stakeholder dissemination 11 workshop. 


\section{Results}

2 Introduction

3 Overall, we identified, validated and customized a total of 304 unique mandated actions

4 and 79 unique legitimate Role-Bearers during MVD management in Uganda. Below, we

5 stratify the actions and legitimate Role-Bearers by phase and selected action areas of

$6 \quad$ MVD management

7 Mandated Actions and Legitimate Role-Bearers per phase of MVD management in

$8 \underline{\text { Uganda }}$

9 We identified, validated and customized 21, 166, 96 and 21 mandated actions under the

10 Mitigation, Preparedness, Response and Recovery Phases of MVD management in

11 Uganda respectively. These are summarized in table 3 . These actions were assigned to

$1236,51,55$ and 28 legitimate Role-Bearers in the Mitigation, Preparedness, Response

13 and Recovery Phases of MVD management respectively. These are summarized in 14 table 4.

15 Mandated Actions ad Legitimate Role-Bearers for selected action areas of MVD

16 management in Uganda

17 Further, the 304 mandated actions were categorized under 26 action areas of MVD

18 management. These action areas are reflected in table 3 . We report on the results of 4

19 out of all the 26 action areas. The 4 selected action areas are Coordination,

20 Surveillance, Resource Mapping and Risk Communication. We identified, validated and

21 customized 86, 16, 3 and 10 mandated actions under Coordination, Surveillance,

22 Resource Mapping and Risk Communication respectively, as summarized in table 4. 
1 Table 3: Summary of MVD management mandated actions and their lead legitimate 2 role-bearers

\begin{tabular}{|c|c|c|c|}
\hline Phase & Action Area & Actions & $\begin{array}{l}\text { Main Actors (No of } \\
\text { actions) }\end{array}$ \\
\hline \multirow[t]{5}{*}{ Mitigation } & Capacity Building & 1 & Line Ministries(1) \\
\hline & Guideline Development & 4 & Line Ministries(4) \\
\hline & Guideline Implementation & 6 & DTF(4), HWs(3) \\
\hline & Risk Assessment & 8 & OPM(4), Line Ministries(3) \\
\hline & Social Mobilization & 2 & DTF(1),Line Ministries(1) \\
\hline \multirow[t]{16}{*}{ Preparedness } & Advocacy & 6 & DTF(5) \\
\hline & Capacity Assessment & 6 & DTF(3), DHT(3), \\
\hline & Capacity Building & 16 & DHT (13), DTF(2) \\
\hline & Capacity Monitoring & 2 & $\mathrm{ESD}(2)$ \\
\hline & Coordination & 33 & $\begin{array}{l}\operatorname{NTF}(12), \mathrm{MoH}-\mathrm{HQ}(19), \\
\operatorname{DTF}(7), \operatorname{DRRT}(9)\end{array}$ \\
\hline & Guidelines Update & 37 & Line Ministries(4) \\
\hline & Guideline Dissemination & 4 & $\mathrm{MoH}-\mathrm{HQ}(4)$ \\
\hline & Laboratory Strengthening & 9 & NTF(7), MoH-HQ(6) \\
\hline & Partner Mapping & 2 & $\operatorname{NTF}(2)$ \\
\hline & Policy Implementation & 2 & Line Ministries(8) \\
\hline & Resource Mapping & 3 & NTF(3) \\
\hline & Resource Mobilization & 16 & $\operatorname{NTF}(17)$ \\
\hline & Risk Assessment & 4 & OPM(4), Line Ministries(3) \\
\hline & Risk Communication & 9 & UNPHLS(4), PHEOC(6) \\
\hline & Simulation Exercises & 1 & 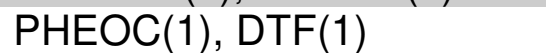 \\
\hline & Surveillance Strengthening & 16 & ESD(10),EOC(9), UVRI(5) \\
\hline \multirow[t]{6}{*}{ Response } & Case management & 14 & DTF(4), DRRT(4), NTF(2) \\
\hline & Coordination & 53 & $\begin{array}{l}\text { NTF(12), MoH-HQ(19), } \\
\text { DTF(7), DRRT(9) }\end{array}$ \\
\hline & Laboratory & 7 & NTF(7), MoH-HQ(6) \\
\hline & Resource Mobilization & 1 & $\operatorname{NTF}(17)$ \\
\hline & Social Mobilization & 5 & NTF(4), DTF(1) \\
\hline & Surveillance & 16 & $\begin{array}{l}\text { WHO(11), ZDCO(5), } \\
\text { PHEOC(3), UVRI(3),RRT(5) }\end{array}$ \\
\hline \multirow[t]{6}{*}{ Recovery } & $\begin{array}{r}\text { Reactivation of routine } \\
\text { services }\end{array}$ & 1 & $\mathrm{DHT}(1)$ \\
\hline & Rehabilitation & 1 & $\mathrm{DHT}(1)$ \\
\hline & Response Evaluation & 5 & DTF(2), MoH-HQ(2) \\
\hline & Risk Communication & 1 & UNPHLS(4), PHEOC(6) \\
\hline & Routine Surveillance & 4 & $\mathrm{DHT}(3)$ \\
\hline & Systems Strengthening & 9 & $\mathrm{MoH}-\mathrm{HQ}(4), \mathrm{DTF}(2), \mathrm{DHT}(1)$ \\
\hline
\end{tabular}


1 Networks of legitimate Role-Bearers during MVD management in Uganda

2 Multiple actor networks were determined. These include an overall actor network, a

3 network for each of the 4 phases of MVD management and a network for a selection of

44 (Coordination, Surveillance, Resource Mapping and Risk Communication) of the 26

5 action areas of MVD management in Uganda. These are shown in figure 3, figure 4 and

6 figure 5 respectively. The quality of these actor networks in terms of degree

7 centralization and density is summarized in table 4 .

$8 \quad$ Table 4: Selected quality metrics of expected actor networks in the different phases and 9 selected action areas of MVD management in Uganda

\begin{tabular}{|c|c|c|c|c|c|}
\hline & $\begin{array}{l}\text { Most } \\
\text { Connected } \\
\text { Actors }\end{array}$ & $\begin{array}{l}\text { Unique } \\
\text { Actors }\end{array}$ & $\begin{array}{l}\text { Total } \\
\text { Connections }\end{array}$ & $\begin{array}{l}\text { Degree } \\
\text { Centralization }\end{array}$ & Density \\
\hline Mitigation & $\begin{array}{l}\text { 1. } \mathrm{MoH}-\mathrm{HQs} \\
\text { 2. DTF } \\
\text { 3. NOHP }\end{array}$ & 36 & 51 & 0.35 & 0.04 \\
\hline Preparedness & $\begin{array}{l}\text { 1. } \mathrm{MoH}-\mathrm{HQs} \\
\text { 2. } \mathrm{DHT} \\
\text { 3. NTF }\end{array}$ & 51 & 179 & 0.64 & 0.07 \\
\hline Response & $\begin{array}{ll}\text { 1. NTF } \\
\text { 2. DRRT } \\
\text { 3. NRRT }\end{array}$ & 55 & 132 & 0.5 & 0.04 \\
\hline Recovery & $\begin{array}{l}\text { 1. MoH-HQs } \\
\text { 2. DTF } \\
\text { 3. NOHP }\end{array}$ & 28 & 35 & 0.63 & 0.05 \\
\hline Coordination & $\begin{array}{l}\text { 1. MoH-HQs } \\
\text { 2. DTF } \\
\text { 3. DDRT }\end{array}$ & 50 & 106 & 0.44 & 0.04 \\
\hline Surveillance & $\begin{array}{l}\text { 1. WHO-CO } \\
\text { 2. UVRI } \\
\text { 3. NNRT }\end{array}$ & 38 & 96 & 0.38 & 0.07 \\
\hline $\begin{array}{r}\text { Resource } \\
\text { Mapping }\end{array}$ & $\begin{array}{l}\text { 1. NTF } \\
\text { 2. DTF }\end{array}$ & 18 & 19 & 0.99 & 0.06 \\
\hline $\begin{array}{r}\text { Risk } \\
\text { Communication }\end{array}$ & $\begin{array}{l}\text { 1. UNPHLS } \\
\text { 2. EOC } \\
\text { 3. NTF }\end{array}$ & 26 & 45 & 0.49 & 0.07 \\
\hline
\end{tabular}


Figure 3: Network of expected actors during MVD management in Uganda; all phases and action areas combined

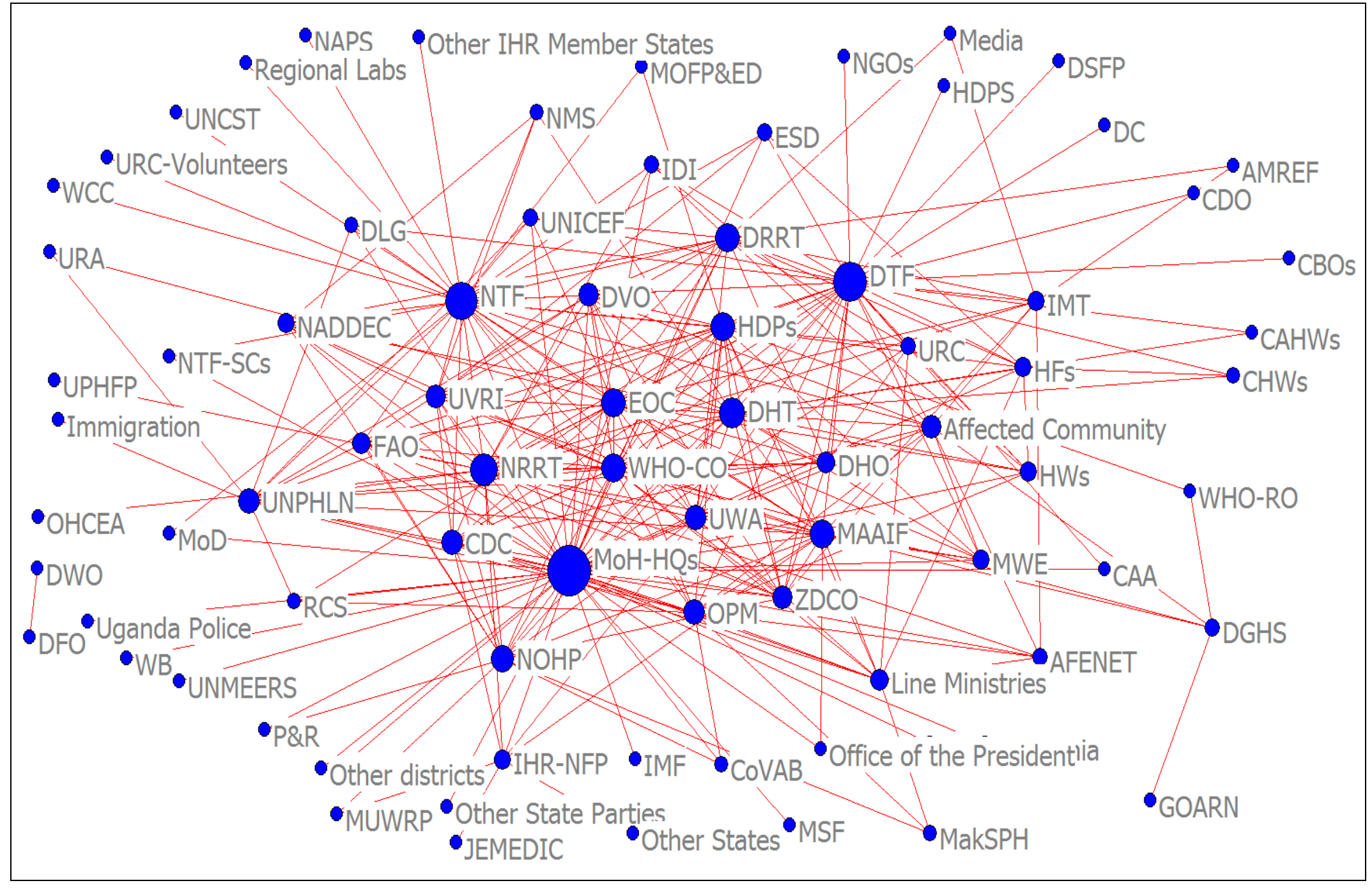

17 | P a g e 
Figure 4: Expected actor networks per phase (mitigation, preparedness, response and recovery) of MVD management

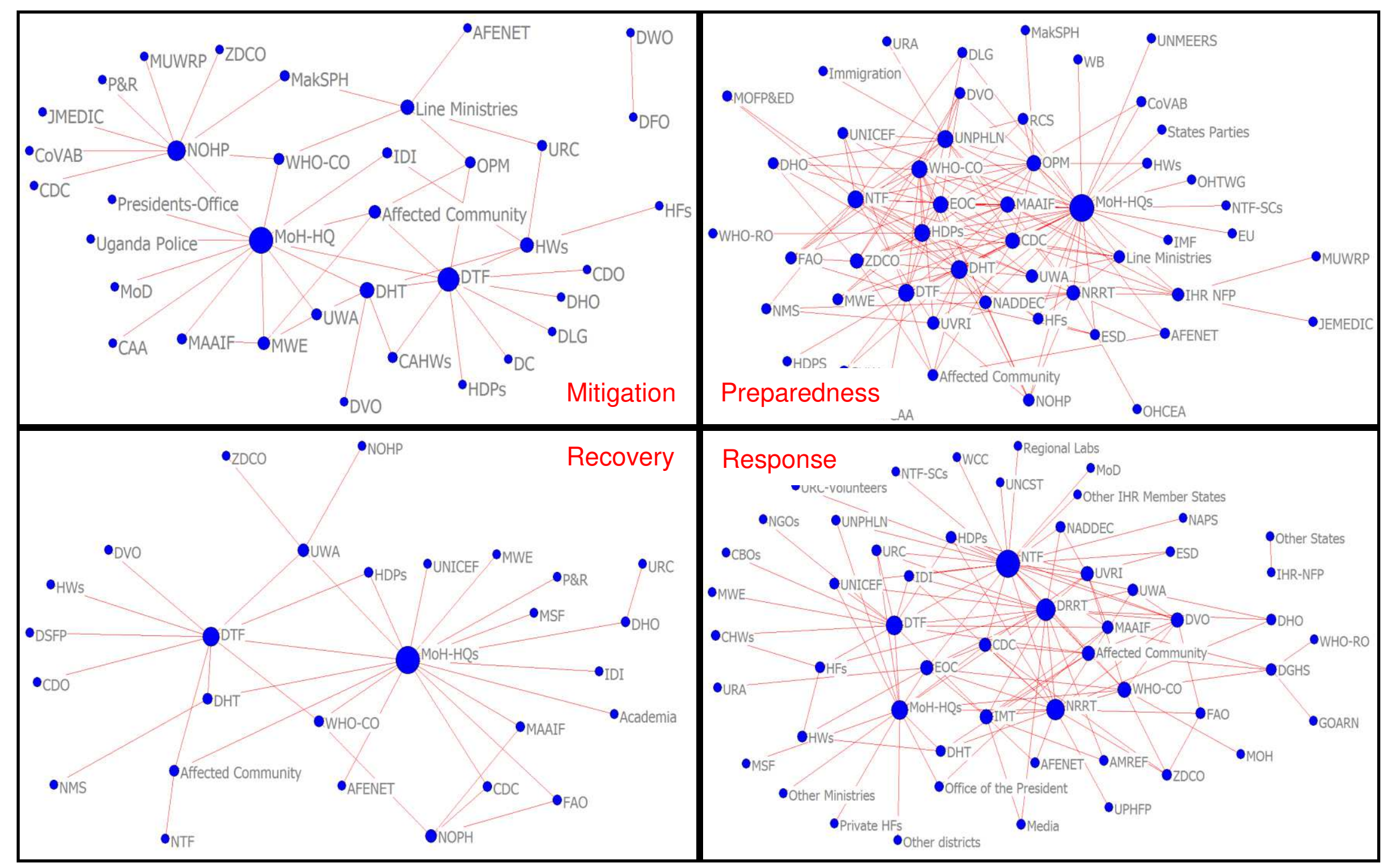

18 | Page 
Figure 5: Expected actor network for selected action areas (MVD Coordination, Surveillance, Resource-Mapping and Risk-Communication)

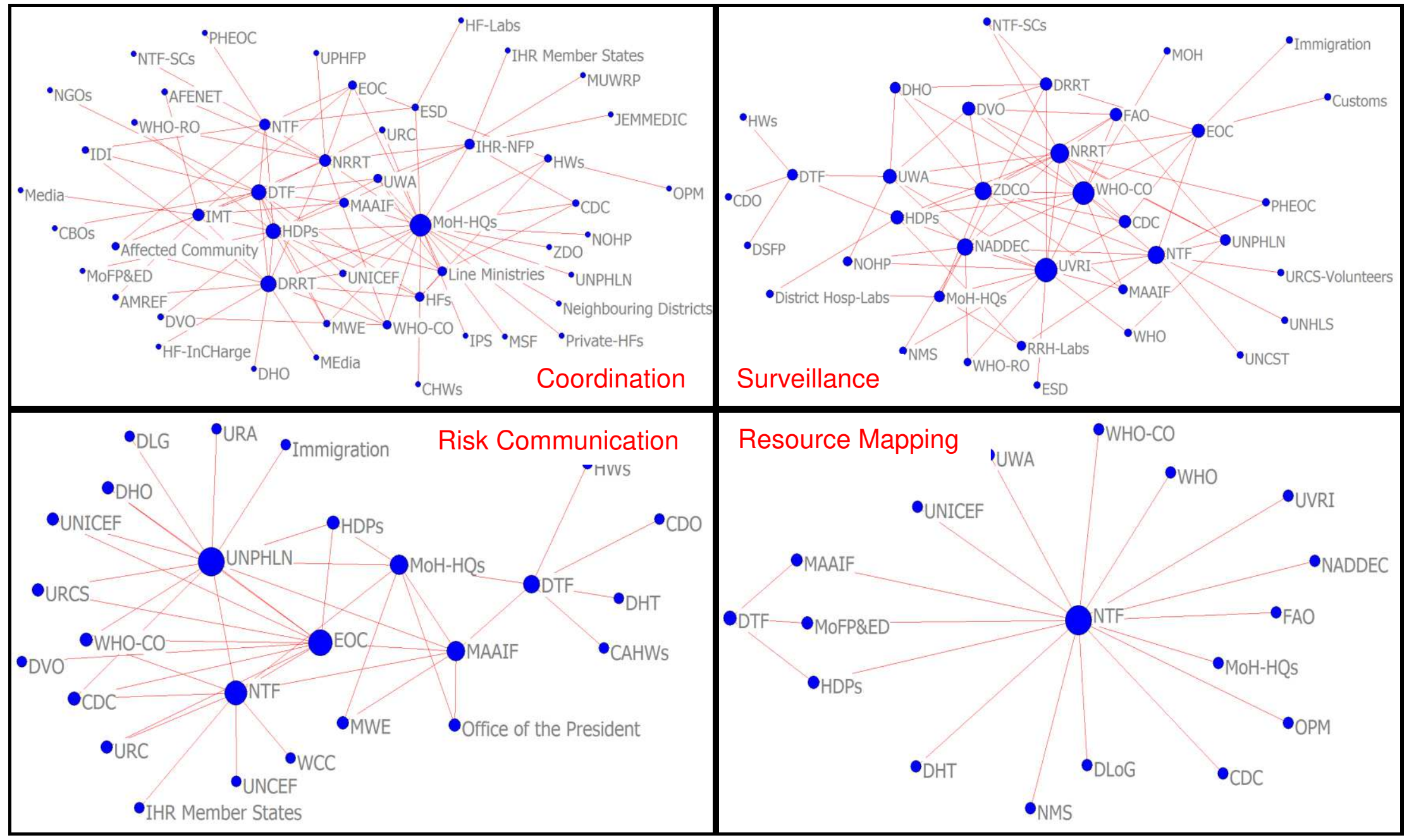

19 | P a g e 


\section{Discussion}

2 Introduction

3 In Uganda, just like it is in many LMICs, management of epidemics should be

4 collaborative endeavor. This is because no single Ministry, Department or Agency

5 (MDA) has the required jurisdictional authority, legitimacy, resources and technical

6 capability to effectively assume command and control of epidemic management alone.

7 By extension, government entities require collaboration with non-state actors such as

8 development partners, private sector and civil society organizations. The requirement to

9 operate interdependently however comes with the inherent challenge that

10 interdependence often reduces the efficiency of outcomes - partly due to increase in

11 inter-agency transaction costs (Williamson, 1981). To reduce the likelihood of outcome

12 inefficiency, the mandated actions, their legitimate role-bearers and the mechanisms for

13 coordinating the multitude of legitimate role-bearers ought to be clear ex ante

14 (Crowston, 1997; Malone \& Crowston, 1994; Melin \& Axelsson, 2005; Nowell et al.,

15 2018). Using the case of Marburg Virus Disease (MVD), we identified, validated and

16 customized the mandated actions, their legitimate role-bearers and expected actor

17 networks in the management of MVD epidemics in Uganda.

18 Mandated actions and legitimate role-bearers during MVD management in Uganda

19 We identified, validated and customized a total of 304 actions expected to be

20 implemented across the four phases of MVD management in Uganda. All the

21 synthesized actions (304) were assigned to specific legitimate lead and led (other) role

22 bearers. We were not able to find any published literature against which to compare 20 | P a g e 
1 whether the determined number of MVD actors (and actions) was small, medium or

2 large. Also, we were not able to find any evidence from Uganda or other LMIC setting

3 on comprehensiveness of allocation of the multiple actors to all the required actions for

4 management of MVD or any other epidemic. Elsewhere, previous studies have however

5 indicated that prior identification of actors and clarification about their mandated roles

6 increases cross-institutional preparedness and response to complex health emergences

7 including but not limited to MVD and other infectious disease epidemics (De Vries et al.,

8 2019; Isken et al., 2008; Joustra, Meurs, \& Fresco, 2012).

9 Expected networks of legitimate Role-Bearers during MVD management in Uganda

10 We elaborated and visualized the expected actor networks by the four (4) phases

11 (Mitigation, Preparedness, Response and Recovery) of MVD management in Uganda.

12 This elaboration was also applied to four action areas (Coordination, Surveillance, Risk

13 Communication and Resource Mapping) selected out of the 26 pragmatic action areas

14 (as reflected in table 3). We indicated the actors who are expected to be central (and

15 peripheral) for each of the four (4) phases and each of the 26 action areas of MVD

16 management in Uganda. Previous studies have underscored for need for prior clarity on

17 the relationship between multiple actors involved in the management of complex

18 situations, especially on the structures and channels of decision making and

19 communication respectively. This facilitates a more coordinated management of

20 complex crises (Moynihan, 2009; Wimelius \& Engberg, 2015).

21 Available literature on global social networks identifies four main types of structural

22 configurations for aligning the actions of multiple stakeholders involved in the same

21 P a g e 
1 problem space (Nowell et al 2018). These are; 1) centralized, 2) closed, 3)

2 brokered/decentralized and 4) core/periphery. Centralized networks are networks in

3 which actors are linked together through a single central actor. Closed networks refer to

4 a network in which there is a high level of connectivity across all actors in the network.

5 Brokered or decentralized network are the ones characterized by sub-networks of

6 actors that are connected together through a series of brokers. A core-periphery

7 network is one characterized by dense connections among a central subgroup of actors

8 at the core of the network surrounded by a peripheral set of actors with more sparse

9 connections (Nowell et al., 2018).

10 Our findings indicate that all the actor networks across the four phases and the 4 of the 1126 action areas of MVD management in Uganda conform to the Core-Periphery 12 structure than any other global social network structure. From our findings, the actors at 13 the core of MVD management in Uganda are NTF, DTF, MoH-HQs, DDRT, NRRT, 14 EOC, WHO-CO and UNPHLN. The actors making up the periphery are highly variable.

15 The Core-Periphery structure of network governance has several advantages (including 16 better coordination) over all other structures. By inference, the coordination of MVD 17 management in Uganda could be considered more effective, because of the core18 periphery structure for aligning the actions of multiple actors during MVD management 19 (Johnson, Boster, \& Palinkas, 2003; Provan \& Lemaire, 2012). We however do not have 20 any evidence yet as to whether this expected core-periphery structure of network 21 governance is observed during actual MVD management in Uganda. 
1 Provan and collegues argue that there are certain critical contingencies that can be

2 used to predict which type of network governance structure would be more effective.

3 These are; 1) The total number of actors involved, 2) The level of trust among the actors

4 involved, 3) The level of goal consensus among the actors involved and 4) the

5 competency of the actors involved (Provan \& Kenis, 2008). On the number of actors

6 involved, Provan and collegues argue that if the number of actors involved is moderate

7 to many, then the core-periphery structure is expected to be the most effective structure

8 to deploy. Apart from resource Mobilization, our findings reveal that the number of

9 expected actors in each of the 4 phases of MVD management and in each of the other

1026 action areas of MVD management is greater than 25. To the extent that is

11 interpreted as a moderate to large number of expected actors, and if MVD management

12 is Uganda is relatively more effective (Mbonye et al., 2014; Okware, 2016), then our

13 findings conform to the propositions stated by Provan and collegues that if the number

14 of actors is moderate to large, the core-periphery structure of network governance is

15 expected to result into more effective coordination of multiple actors working in the

16 same problem space (Provan \& Kenis, 2008).

17 The expected quality of actor networks during MVD management in Uganda

18 The ego-centric quality of expected networks in the comprehensive management of 19 MVD in Uganda was determined. In ego-centric Social Network Analysis (SNA), there 20 are multiple metrics that can be used to report on the quality of a social network. We 21 opted for centralization and density; some of the commonly used metrics in ego-centric

22 SNA. Density is perhaps the most well-known network metric and represents the degree 
1 to which all actors are connected to all other actors in the network, the notion of network

2 closure. centralization focuses on the degree the network is organized around a single

3 actor or set of actors (Hawe, Webster, \& Shiell, 2004).

4 The expected core actors across all the visualized MVD management related networks

5 are NTF, DTF, MoH-HQs, DDRT, NRRT, EOC, WHO-CO and UNPHLN. Core actors

6 were connected to the largest number of actors and therefore expected to be the most

7 critical actors in the MVD management networks in Uganda. If resources and mandate

8 to coordinate MVD outbreaks is built among these core agencies, inefficiencies in the

9 functionality of the whole network of actors can be improved. By practice and 10 observation, these actors have always been at the core of MVD management in

11 Uganda. The overall density and centralization of the MVD networks ranged from 0.04-

$12 \quad 0.07$ and $0.35-0.99$ respectively. The density was low because the networks are

13 predominantly core-periphery with few core actors and many peripheral actors (Provan

14 \& Lemaire, 2012). For the same reason, centralization of the expected MVD

15 management actor networks is high.

16 Development of basis for exploring stakeholder deviations from mandated actions

17 during MVD management

18 We recognize that the actions elaborated in this paper will likely be more constant than

19 the elaborated actors. We also recognize that the elaborated actor interlinkages during

20 the four phases and 4 of the 26 action areas of MVD management need not to be rigid.

21 In fact, in the face of a rapidly changing complex emergency, ad hoc structures of actor

22 management are sometimes more efficient, resulting into a more effective crisis 
1 response (Huizer, Kraaij-Dirkzwager, Timen, Schuitmaker, \& van Steenbergen, 2015;

2 Weick, 2005). The findings from this study provide a basis for exploring compliance and

3 deviations from expected action and actor inter-linkages during the management of

4 future MVD outbreaks in Uganda

5 Conclusion

6 Mandated actions and legitimate role-bearers during MVD management in Uganda are

7 multiple and highly inter-dependent. The inter-dependencies are mostly mediated by

$8 \mathrm{MoH}-\mathrm{HQs}$, NTF and DTF as the most central and legitimate agencies across all the

9 phases and action areas of MVD management in Uganda. These are therefore 10 expected to play a leadership role in information processing, information sharing,

11 decision making and command and control during MVD management in Uganda.

\section{Recommendations}

13 The study findings can be used as the basis for exploring compliance and deviation in

14 mandated actions and legitimate role-bearers during the actual management of future

15 MVD epidemics in Uganda.

16 To improve the effectiveness of MVD management, it is important to build the capacity

17 of the agencies at the center of MVD management in the core mechanisms of 18 coordination.

19 The methodological approach employed in thus study could be replicated to other 20 infectious disease epidemics in Uganda and beyond to aid the management and 21 resilience of health systems in the face of future epidemics.

22 


\section{List of Abbreviations}

2 AFENET: African Field Epidemiology Network

3 AMREF: African Medical and Research Foundation

4 CAA: Civil Aviation Authority

5 CAHWs: Community Animal Health Workers

6 CBOs: Community Based Organizations

7 CCHF: Crimean Congo Hemorrhagic Fever

8 CDC: $\quad$ Centers for Disease Control and Prevention

9 CHWs: Community Health Workers

10 CoVAB: Collage of Veterinary and Agricultural Business

11 DGHS: Director General of Health Services

12 DHT: District Health Team

13 DRRT: District Rapid Response Team

14 DSFP: District Surveillance Focal Person

15 DTF: District Task Force

16 DVO: District Veterinary Officer

17 EMC: Emergency Management Cycle

18 ESD: Epidemiology and Surveillance Division

19 EU: $\quad$ European Union

20 GOARN: Global Outbreak Alert and Response Network

21 HDPs: Health Development Partners

22 HFs: Heath Facilities

23 HDREC: Higher Degrees Research and Ethics Committee

24 HPAl: Highly Pathogenic Avian Influenza

25 HWs: Health Workers

26 IDI: Infectious Disease Institute

27 IDSR: Integrated Disease Surveillance and Response

28 IHR: International Health Regulations

29 IMF: International Monetary Fund

30 IMT: Incident Management Team

31 IRB: Institutional Review Board

32 JEE: Joint Enteral Evaluation

33 JMEDICC: Joint Mobile Emerging Disease Intervention Clinical Capacity

34 LMICs: Low and Middle Income Countries

35 MAAIF: Ministry of Agriculture Animal Industry and Fisheries

36 MakSPH: Makerere University School of Public Health 
1 MoD: $\quad$ Ministry of Defense

2 MOFP\&ED: Ministry of Finance, Planning and Economic Development

3 MoH-HQs: Ministry of Health Headquarters

4 MSF: Médecins San Frontieres

5 MUWRP: Makerere University Walter Reed Project

6 MVD: $\quad$ Marburg Virus Disease

7 NADDEC: National Animal Disease Diagnostics and Epidemiology Center

8 NAO: Network Administrative Organization

9 NAPS: National Action-Plan for Health Security

10 NGOs: Non-Governmental Organizations

11 NMS: National Medical Stores

12 NRRT: National Rapid Response Team

13 NTF: National Task Force

14 OHCEA: One Health Central and East Africa

15 OPM: Office of the Prime Minister

16 P\&R: $\quad$ Predict and Respond

17 PHEOC: Public Health Emergency Operations Center

18 RRT: Rapid Response Team

19 RVF: Rift Valley Fever

20 SNA: Social Network Analysis

21 SSA: Sub Saharan Africa

22 UCRS: Uganda Catholic Relief Services

23 UNCST: Uganda National Council of Science and Technology

24 UNICEF: United Nations Children Education Fund

25 UNMEER: United Nations Mission for Ebola Emergency Response

26 UNPHLS: Uganda National Public Health Laboratory Services

27 URC: Uganda Red Cross

28 USAID: United States Agency for International Development

29 UVRI: Uganda Virus Research Institute

30 UWA: Uganda Wildlife Authority

31 WB: World Bank

32 WHO: World Health Organization

33 WHO-CO: World Health Organization Country Office

34 WHO-RO: World Health Organization Regional Office

35 ZDCO: Zoonotic Disease Coordination Office 
Declarations

2 Ethics approval and consent to participate: Ethical approval for this study was

3 provided by Makerere University Higher Degree Research and Ethics Committee

4 (HDREC Protocol number 580) and granted permission from Ministry of Health

5 Headquarters was also granted (Ref Number ADM.105/309/16). We determined the

6 judicious use of agency names in the findings using the overriding principle of do no

7 harm, practical application of the study and the need for relationship management with

8 known agencies that play key roles in MVD management in Uganda. Participation as a

9 Delphi panel member was voluntary. Informed consent was also sought and

10 documented. We shared the study findings at a national level stakeholder dissemination

11 workshop.

12 Consent for publication: Not applicable.

13 Availability of data and materials: The datasets used and/or analyzed during for our 14 study are available from the corresponding author upon reasonable request.

15 Competing interests: The authors declare that they have no competing interests

16 Funding: This work was funded by the Supporting Policy Engagements for Evidence

17 based Decisions (SPEED) for Universal Health Coverage Project at Makerere 18 University School of Public Health (MakSPH). SPEED is supported by European Union.

19 The contents of this article are however solely the responsibility of the authors and do 20 not necessarily represent the views of the SPEED project or MakSPH. 
1 Authors' contributions: SS, TD, BS, SA and SF conceptualized the study. KJ and MI

2 acquired the documents for the literature review. SS, TD, NR and TKA conducted the

3 data abstraction, analysis and synthesis. SS, TD, NR, TKA AND SF facilitated the

4 Delphi survey. SF facilitated the engagement after the first round of the Delphi survey.

$5 \mathrm{KJ}$ and $\mathrm{MI}$ mobilized the Delphi panel participants and hosted the Delphi survey at the

6 Public Health Emergency Operations Center. SS prepared the first draft of the

7 manuscript. All the authors revised the various drafts of the manuscript. All authors read

8 and approved the final manuscript.

9 Acknowledgements: The authors express their gratitude to the SPEED project for 10 funding the study. The authors also acknowledge the support given of the Public Health

11 Emergency Operations Center (PHEOC), Uganda Ministry of Health and members of

12 who participated in the Delphi panel. Special thanks to Annet Joselyn Atuhairwe who

13 also took part in the data abstraction. However, the views expressed in the paper are

14 solely of the authors and do not reflect that of the organizations they are affiliated with.

15

16

17

18

19

20

21

22

23

24

25

26

27 


\section{References}

Ario, A. R., Makumbi, I., Nkonwa, I., Eyu, P., Opio, N., Nakiire, L., . . Aceng, J. (2020). Investigation of Marburg Virus Disease Outbreak in Kween District, Eastern Uganda, 2017. 4, 2. doi: 10.33140/AIDT.04.01.02

Banipal, K. (2006). Strategic approach to disaster management: lessons learned from Hurricane Katrina. Disaster Prevention and Management: An International Journal, 15(3), 484-494. doi: doi:10.1108/09653560610669945

Butts, C. T. (2008). Social network analysis: A methodological introduction. Asian Journal of Social Psychology, 11(1), 13-41.

CDC. (2020). National center for Emerging and Zoonotic infectious diseases (NCEZID). Viral Special Pathogens branch (VSPB).

Crowston, K. (1997). A Coordination Theory aproach to Organizatinoal Process Design. Organizational Science, 8(2), 157-175. doi: 10.1086/501473

De Vries, M., Kenis, P., Kraaij-Dirkzwager, M., Ruitenberg, E. J., Raab, J., \& Timen, A. (2019). Collaborative emergency preparedness and response to crossinstitutional outbreaks of multidrug-resistant organisms: a scenario-based approach in two regions of the Netherlands. BMC public health, 19(1), 52.

FEMA. (2001). Federal Emergency Management Agency (FEMA) Situation Reports. September 11- October 04.

Fenollar, F., \& Mediannikov, O. (2018). Emerging infectious diseases in Africa in the 21st century. New microbes and new infections, 26, S10-S18.

Frieden, T. R., \& Damon, I. K. (2015). Ebola in West Africa-CDC's Role in Epidemic Detection, Control, and Prevention. Emerging Infectious Diseases, 21(11), 18971905. doi: $10.3201 /$ eid2111.150949

Giannarou, L., \& Zervas, E. (2014). Using Delphi technique to build consensus in practice. International Journal of Business Science \& Applied Management (IJBSAM), 9(2), 65-82.

Gostin, L. O., \& Friedman, E. A. (2015). A retrospective and prospective analysis of the west African Ebola virus disease epidemic: robust national health systems at the foundation and an empowered WHO at the apex. The Lancet, 385(9980), 19021909.

Habibi, A., Sarafrazi, A., \& Izadyar, S. (2014). Delphi technique theoretical framework in qualitative research. The International Journal of Engineering and Science, 3(4), 8-13.

Hanneman, R. A., \& Riddle, M. (2005). Introduction to social network methods: University of California Riverside.

30 | P a g e 
Hawe, P., Webster, C., \& Shiell, A. (2004). A glossary of terms for navigating the field of social network analysis. Journal of Epidemiology \& Community Health, 58(12), 971-975.

Huizer, Y. L., Kraaij-Dirkzwager, M. M., Timen, A., Schuitmaker, T. J., \& van Steenbergen, J. E. (2015). Context analysis for epidemic control in the Netherlands. Health policy, 119(1), 66-73.

Isken, L., Roorda, J., de Kok, L., Kaur, P., van Ouwerkerk, I., \& Stenvers, O. (2008). Evaluatie Salmonella Typhimurium ft 560 uitbraak in Twente 2006. Bilthoven: RIVM, GGD Regio Twente, VWA.

Johnson, J. C., Boster, J. S., \& Palinkas, L. A. (2003). Social roles and the evolution of networks in extreme and isolated environments. Journal of Mathematical Sociology, 27(2-3), 89-121.

Joustra, T., Meurs, P., \& Fresco, L. (2012). Salmonella in gerookte zalm.

Kruk, M. E., Myers, M., Varpilah, S. T., \& Dahn, B. T. (2015). What is a resilient health system? Lessons from Ebola. The Lancet, 385(9980), 1910-1912.

Malone, T., \& Crowston, K. (1994). The interdisciplinary study of coordination. ACM Computer Survey, 26(1), 87-119.

Mbonye, A., Wamala, J., Nanyunja, M., Opio, A., Aceng, J., \& Makumbi, I. (2014). Ebola viral hemorrhagic disease outbreak in West Africa - lessons from Uganda. African Health Sciences.

Mboussou, F., Ndumbi, P., Ngom, R., Kamassali, Z., Ogundiran, O., Van Beek, J., . . . Impouma, B. (2019). Infectious disease outbreaks in the African region: overview of events reported to the World Health Organization in 2018. Epidemiology \& Infection, 147.

Melin, U., \& Axelsson, K. (2005). Understanding Organizational Coordination and Information Systems-Mintzberg's Coordination Mechanisms Revisited and Evaluated. Paper presented at the 13th European Conference on Information Systems, Regennsburg, Germany.

$\mathrm{MoH}$. (2012). Uganda Natinoal Technical Guidelines for Integrated Disease Surveillance and Response (pp. 251-254).

$\mathrm{MoH}$. (2017). Uganda Declares End of Marburg Virus Disease Outbreak [Press release] Moynihan, D. P. (2009). The network governance of crisis response: Case studies of incident command systems. Journal of public administration research and theory, 19(4), 895-915. 
Nowell, B., Steelman, T., Velez, A.-L. K., \& Yang, Z. (2018). The structure of effective governance of disaster response networks: Insights from the field. The American Review of Public Administration, 48(7), 699-715.

Nyakarahuka, L., Shoemaker, T. R., Balinandi, S., Chemos, G., Kwesiga, B., Mulei, S., . .. Masiira, B. (2019). Marburg virus disease outbreak in Kween District Uganda, 2017: Epidemiological and laboratory findings. PLoS neglected tropical diseases, 13(3), e0007257.

Okware, S. I. (2016). Managing Ebola in Low-resource Settings: Experiences from Uganda. (PhD).

Olu, O. O., Lamunu, M., Chimbaru, A., Adegboyega, A., Conteh, I., Nsenga, N., . . . Dafae, F. M. (2016). Incident management systems are essential for effective coordination of large disease outbreaks: perspectives from the coordination of the Ebola outbreak response in Sierra Leone. Frontiers in public health, 4, 254.

Provan, K. G., \& Kenis, P. (2008). Modes of network governance: Structure, management, and effectiveness. Journal of public administration research and theory, 18(2), 229-252.

Provan, K. G., \& Lemaire, R. H. (2012). Core concepts and key ideas for understanding public sector organizational networks: Using research to inform scholarship and practice. Public Administration Review, 72(5), 638-648.

Ross, E., Welch, G. H., \& Angelides, P. K. (2017). Sierra Leone's response to the Ebola outbreak: Management strategies and key responder experiences: Chatham House for the Royal Institute of International Affairs.

Ssendagire, S., Tuhebwe, D., Kayongo, S. B., \& Ssengooba, F. (2018). Recommendations to Improve Health System Resilience to Disease Outbreaks in Uganda. UNIVERSAL HEALTH COVERAGE IN UGANDA, 350.

Waugh, W. L. (1999). Living with hazards, dealing with disasters: An introduction to emergency management: ME Sharpe.

Weick, K. E. (2005). 5 Managing the unexpected: complexity as distributed sensemaking Uncertainty and surprise in complex systems (pp. 51-65): Springer.

Whittaker, H. (1979). Comprehensive Emergency Management: A Governor's Guide. Washington DC: National Governors' Association: Center for Policy Research.

Williamson, O. E. (1981). The economics of organization: The transaction cost approach. American journal of sociology, 87(3), 548-577.

Wimelius, M. E., \& Engberg, J. (2015). Crisis Management through Network Coordination: Experiences of $S$ wedish Civil Defence Directors. Journal of Contingencies and Crisis Management, 23(3), 129-137. 
33 | P a g e 


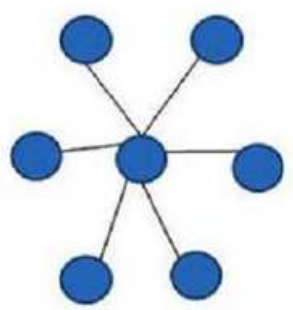

Centralization

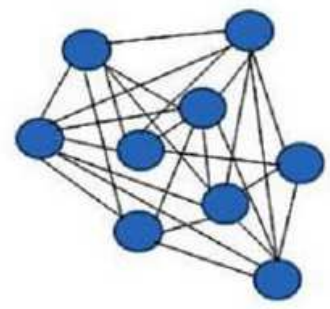

Closure

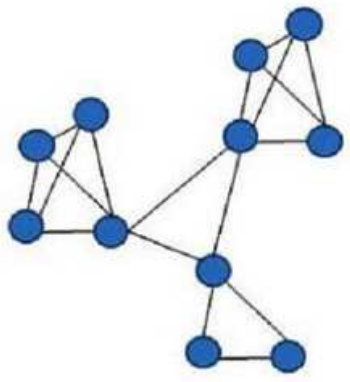

Brokerage

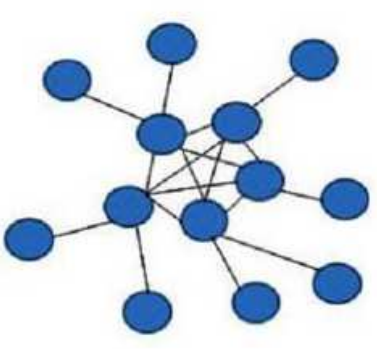

Core/Periphery

Figure 1

Types of Global Network Configuration Structures as described by Nowell and colleagues (Nowell, Steelman, Velez \& Yang, 2018).

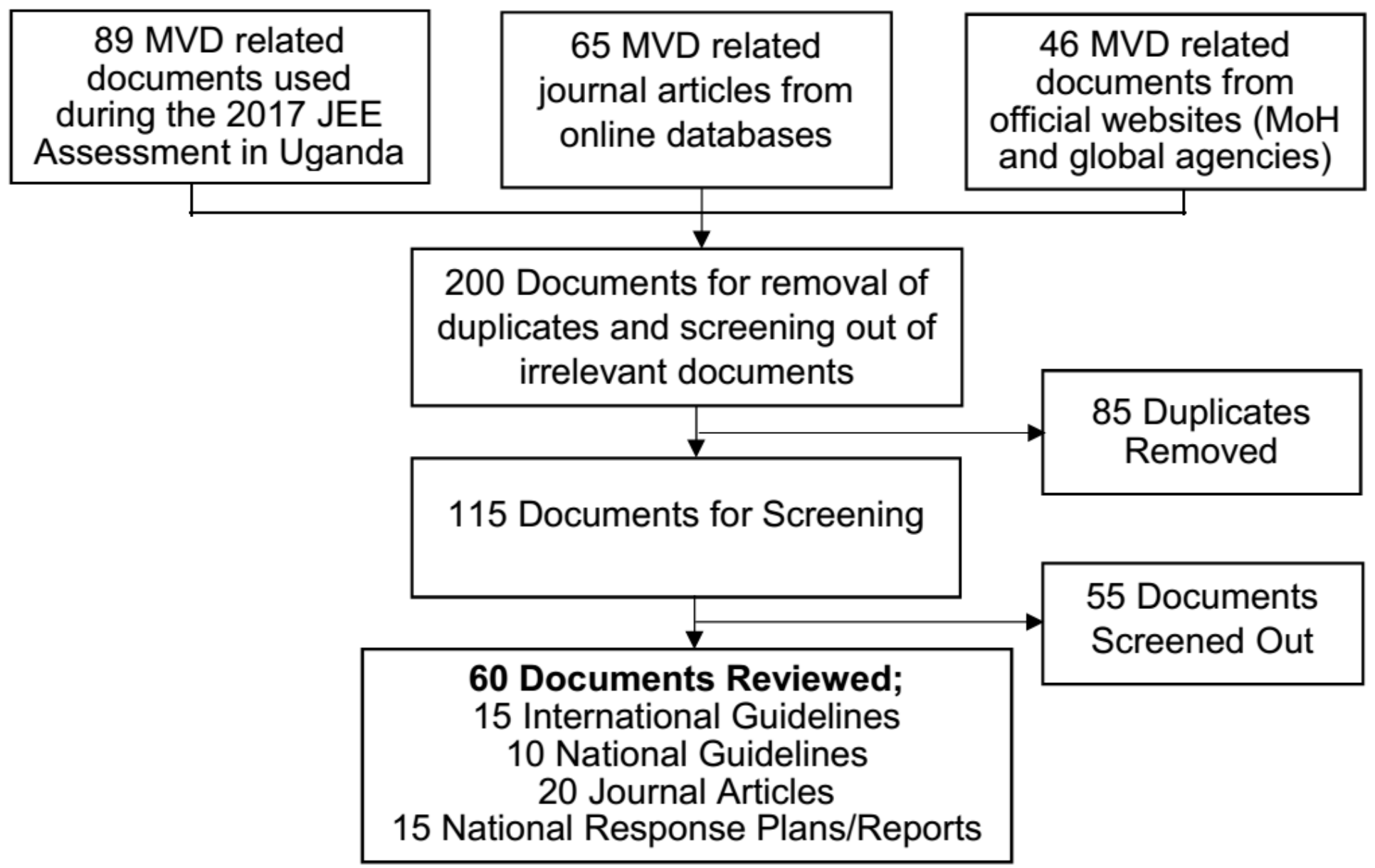

Figure 2 


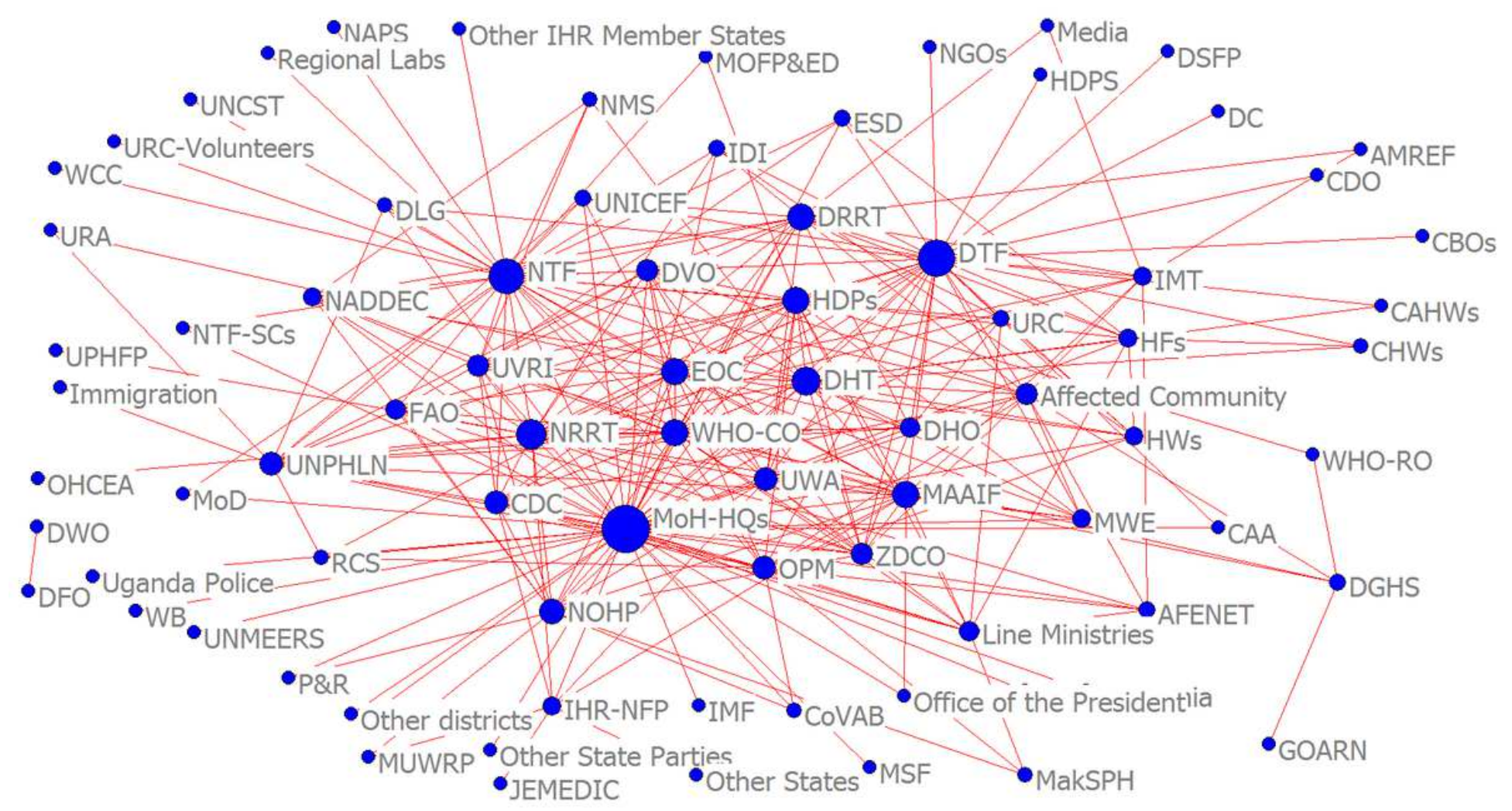

Figure 3

Network of expected actors during MVD management in Uganda; all phases and action areas combined

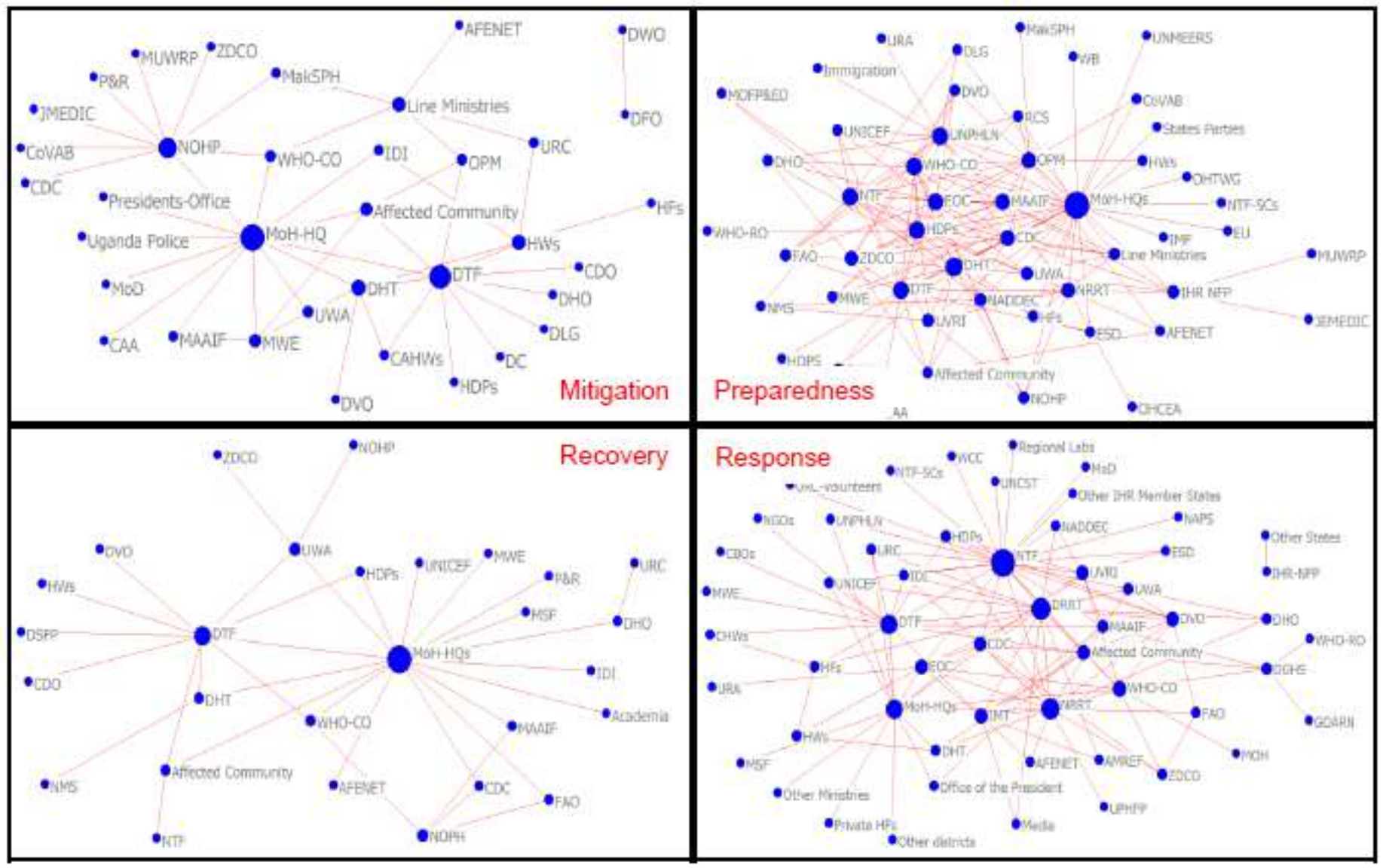


Figure 4

Expected actor networks per phase (mitigation, preparedness, response and recovery) of MVD management

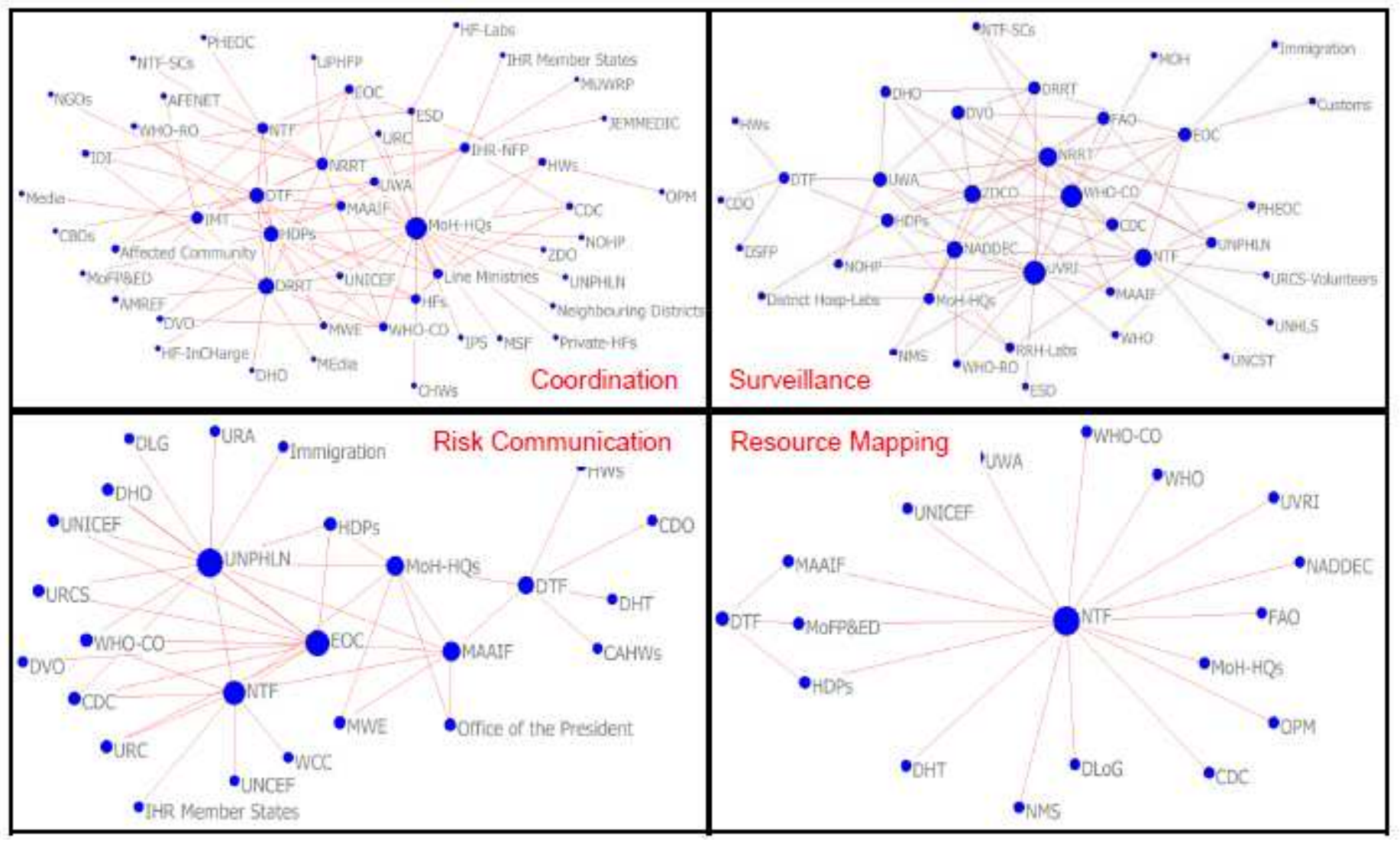

Figure 5

Expected actor network for selected action areas (MVD Coordination, Surveillance, Resource-Mapping and Risk-Communication) 